\title{
An Empirical study on the importance of Task Shifting in current Health Care System
}

\author{
Architha Aithal ${ }^{1}$, Ateendra $\mathrm{Jha}^{2}$ \\ ${ }^{1}$ Second Year Pharm D. Student, Srinivas College of Pharmacy, Mangalore, 574143, India \\ ${ }^{2}$ Department of Pharmacy Practice, Srinivas College of Pharmacy, Mangalore, 574143, India \\ Email Address: aithalarchitha@gmail.com
}

Type of the Paper: Research Paper.

Type of Review: Peer Reviewed.

Indexed in: OpenAIRE.

DOI: http://dx.doi.org/ 10.5281/zenodo.438334.

Google Scholar Citation: $\underline{\text { IJMTS }}$

\section{How to Cite this Paper:}

Architha Aithal, \& Ateendra Jha. (2016). An Empirical study on the importance of Task Shifting in current Health Care System. International Journal of Management, Technology and Social Sciences (IJMTS), 1(1), 21-32.

DOI:http://dx.doi.org/ 10.5281/zenodo.438334.

International Journal of Management, Technology, and Social Sciences (IJMTS)

A Refereed International Journal of Srinivas University, India.

(C) With Authors.

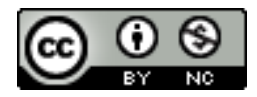

This work is licensed under a Creative Commons Attribution-Non Commercial 4.0 International License subject to proper citation to the publication source of the work.

Disclaimer: The scholarly papers as reviewed and published by the Srinivas Publications (S.P.), India are the views and opinions of their respective authors and are not the views or opinions of the SP. The SP disclaims of any harm or loss caused due to the published content to any party. 


\title{
An Empirical study on the importance of Task Shifting in current Health Care System
}

\author{
Architha Aithal ${ }^{1}$, Dr. Ateendra Jha ${ }^{2}$ \\ ${ }^{1}$ Second Year Pharm D. Student, Srinivas College of Pharmacy, Mangalore, 574143, India \\ ${ }^{2}$ Department of Pharmacy Practice, Srinivas College of Pharmacy, Mangalore, 574143, India \\ Email Address : aithalarchitha@gmail.com
}

\begin{abstract}
Many developing countries are facing a crisis in human health resources due to a critical shortage of health workers. Despite of many trained health care professionals our health care system is struggling to provide optimum services to the patients. Gaps still exist with respect to patient care, which are unevenly delivered. The data collected from 228 subjects reveals that only $7.01 \%$ of the subjects have received counseling always, $59.65 \%$ think that counseling should be given and only $41.66 \%$ are satisfied with current health care system while $56.57 \%$ are not satisfied. Our study shows that there is a huge burden on health care professionals due to a high number of the patient load which leads to the hindrance in optimum patient care and finally leads to the degradation in the quality of health care services. Now time has approached when the term task shifting should be taken seriously especially in the health care sectors. Pharmacists, an ignored profession in the health care sector have a crucial role for optimum patient care. It is the demand of the scenario that pharmacist should be taken as a key role player between the patient and prescriber. A proper communication between the patient and prescriber can be established only if all health care professionals will start working to assist each other not to compete with each other.
\end{abstract}

Keywords: Task shifting, Healthcare system, Patient care, Role of pharmacists in health care.

\section{INTRODUCTION :}

Many developing countries are facing a crisis in human health resources due to a critical shortage of healthcare workers. This shortage is compounded by a high burden of infectious diseases, emigration of trained professionals, difficult working conditions, and low motivation by country governments. Consequently, for example, the burden of chronic diseases like HIV/AIDS has led to the concept of task shifting between healthcare workers and being increasingly promoted as a way of rapidly expanding human resource capability. Such process refers to the delegation of health and medical service responsibilities from higher to lower cadres of health staff, and in some cases even to non-professionals [1-2]. The delegation of tasks from one cadre to another, previously often called substitution [3], is not a new concept. It has been used in many countries and for many decades, either as requirements to emergency needs or as a method to provide adequate healthcare service at primary and secondary levels, especially in rural and urban health centres with understaffed facilities, and also to enhance quality and reduce costs [4]. However, rapidly increasing the need of healthcare generated by the HIV/AIDS epidemic, accelerating trained human resource crises, and unrest in many African countries, which contribute to the collapse or near-collapse of public health systems and increasing health service inequalities to the needy patients within and between 
countries, have given the solution in the form of the concept and practice of task shifting as new prominence and urgency. Gaps are still existing with respect to the health programmes, which are unevenly delivered for needy people, with rural areas being particularly under-serviced, insufficient support for healthcare in healthcare services, and irregular and inconsistent identification and treatment of more common communicable diseases. This leads to the suggestion of strengthening the concept of task shifting to skilled people available in relative/paramedical areas.

The World Health Organization advocates a quick solution to the stated deficiency of professional health workers by means of task-shifting, the process of transferring clinical care responsibilities from more specialized professionals to less specialized health workers through proper delegation, as a strategy to realize the United Nations Millennium Development Goals [2]. For example, it is estimated that sub-Saharan African countries need to triple their current health workforce in order to bring up it close to reach the level as expected by the Health Millennium Development Goals [5]. Accordingly, by shifting the task of providing health services from higher to lower cadres of health staff based on providing sufficient training to handle the situations, the organizations and the countries can find solutions to the shortage of health workers. More precisely, Task Shifting describes a situation where a patient care task normally carried out by a physician is transferred to a health professional with a different but related or lower level of education and training, or to a person trained specifically to perform a limited task only for a short period, without having a formal health education. The rationale behind the concept of applying task shifting idea in developing countries is that the alternative would be no care as health systems are impeded by the shortage of growing health workforce and imbalance in the distribution [6]. Innovative solutions are therefore required to quickly expand the health workforce in an emergency to meet the demand to care for chronic disease. In this article, we study and discuss the growing evidence in support of expanding workforce strategies for chronic disease management in developing countries like India. In this paper, instead of using trained nurses and lay-people (family members and friends) as peer supporters as studied in many task shifting research studies, we have suggested to use paramedical professionals like pharmacists to extend the education and follow-up of patients with chronic diseases beyond clinical settings and improve adherence and treatment outcomes.

\section{LITERATURE REVIEW :}

The shortage of professional health workers in developing countries supports the new effective strategy of task shifting is beneficial in which community or lay health workers (may be oversight from professional health-care practitioners) provide 'front-line' healthcare, instead of physicians and trained nurses [7]. The diseases which have chronic conditions, including infection with the HIV (human immunodeficiency virus) or AIDS (acquired immunodeficiency syndrome) [8-9], diabetes mellitus [10] and some mental disorders.[11-15] need special care for long duration and hence require more attention from physicians and trained nurses.

Task shifting is implemented in several countries as a pragmatic response to health workforce shortages to various degrees, and hence extensive evidence is available in the literature that different types of task shifting have been adopted informally to solve the shortage of human resource needs throughout past history. These guidelines, recommendations, policies, and objectives to 
promote a formal framework that can accept task shifting as a national strategy for organizing the health workforce [2]. In several studies, supportive healthcare provided by lay health workers in the immediate vicinity of the patient has been found to be successful in the primary care of depression and/or anxiety in low-or middleincome countries.[16-18].

The task shifting model illustrates a return to the core principles of health services having characteristics like accessibility, equitability and of good quality. Such recommendations and guidelines on task shifting provide a framework in which access to health services can be extended to all people in a way that is effective and sustainable. It is for these reasons task shifting as the vanguard for the renaissance of primary health care [2]. Evaluation of economic factors of a task-shifting intervention for the treatment of anxiety and depressive disorders in primary-care settings is carried out by Christine Buttorff et al. (2012) in Goa, India [7] using Cost-utility and cost-effectiveness analyses performed in 24 public and private primary-care facilities in Goa and found that within the use of lay health workers in the care of subjects with common mental disorders was not only cost-effective but also cost-saving.

Lehmann et al. (2009) [19] argued that, even though task shifting holds great promise, its long-term success hinges on serious political and financial commitments. The effective implementation of task shifting needs a comprehensive and integrated reconfiguration of health teams, changed scopes of practice, regulatory frameworks, enhanced training infrastructure, and the availability of reliable funding with the time frames of twenty to thirty years instead of three to five years. The concept and practice of community participation need to be revisited. They also argued that task shifting strategies require leadership from national governments to ensure supporting regulatory framework, regulating the implementation of enabling policies, support and guide training institutions, and ensure adequate resources, and using the support of the multiple stakeholders. With such willingness, attitude, and leadership to learn from those with relevant experience (for example, various countries from Africa like Brazil, Ethiopia, Malawi, Mozambique, and Zambia), task shifting can make a vital contribution to building cost-effective, balanced, sustainable, and equitable health care systems. They also suggested that any serious commitment to task shifting requires leadership from country governments. The country government's role is to ensure an enabling policy, regulatory framework, and credentialing system, to accelerate the implementation of relevant policies and to provide required resources, guide and support training institutions to not only upgrade current training but also ensure appropriate initial and continuing education (integrated, multidisciplinary, communityand outcomes-based).

Based on a systematic literature review, Callaghan et al; (2010) [20] found that task shifting is an effective strategy for addressing shortages of health professionals in HIV treatment and care in African countries. Task shifting offers high-quality, cost-effective and quick healthcare to more patients than a physician-centered model. The major challenges of task shifting include adequate training and sustainable support and motivation for staff in new roles, the acceptance and adding new members to healthcare teams, and the compliance of regulatory bodies. Careful implementation of task shifting should be considered where health professionals shortages threaten rollout programmes. They also concluded that task shifting is a viable and rapid response to human resources crisis in HIV care. This paper argues that focus is 
not to determine whether task shifting is possible or effective, but to define the constraints/limits of task shifting and determine where it can have the most sustainable and strongest impact [20].

In another review on Health workforce skill mix and task shifting in low income countries during 2011 by Fulton et al. [21], selected and analyzed thirty-one studies published during 2006 to 2010, based on the strength of evidence and found that task shifting is a promising policy option to increase the productive efficiency of health care services delivery, enhancing a number of services provided with proper quality and cost. According to them, future studies should examine the development of new professional cadres that emerge with and labour markets and developments in automated technology. The paper suggested to strengthening the evidence, skill mix changes need to be evaluated with a rigorous research design to determine the effect on patient health outcomes, quality of care, and costs.

Lekoubou et al (2010) [22] discussed the growing evidence in support of nurse-led strategies for chronic disease management in sub-Saharan Africa, with a focus on hypertension and diabetes mellitus. As per their study, the scarcity in density and distribution of health workforce suggest that sub-Saharan Africa cannot provide solutions to the increasing demand for the healthcare of frequent infectious diseases together with the chronic diseases. Therefore to rapidly expand the health workforce, innovative approaches are needed. The authors also studied and discussed the evidence in support of nurse-led strategies for chronic disease management in sub-Saharan Africa, with a focus on hypertension and diabetes mellitus [22].

The concept of surgical task shifting is proposed in many kinds of research [23] where non-physician clinicians (NPCs) are trained to perform simple life-saving surgical and anesthetic tasks. For example, the most common procedures suggested for task shifting which can be safely managed by non-surgeons are dilation and curettage, and caesarean sections, while the most common general surgical procedures suggested for task shifting are suturing of wounds and manipulation of fractures. Many studies have shown and evaluated that task shifting in surgery have concluded that NPC cadres are safe and effective in terms of quality and cost [24-25]. Chu et al. (2009) also suggested that efforts should focus on training, supervision, and recognition for these de facto surgeons and anaesthesiologists who are professionals in paramedical sciences but capable of doing task shifting jobs with little or no extra training [23].

The above research results on task shifting inspired to conduct a feasible study on task shifting requirement based on the satisfaction level of people in availing healthcare services in India a developing country.

\section{OBJECTIVE AND METHODOLOGY OF PRESENT EMPIRICAL STUDY :}

This type of study is necessary to align investment in human resources for health care services with the current and future needs of the population and of health systems, taking account of the supply market dynamics and education policies of the country, to address the shortages and improve distribution of health workers, so as to enable maximum improvements in health outcomes, social welfare, employment creation, and economic growth. The objective of the work is to assess the gaps in the healthcare system in order to fullfill the needs of patients who are suffering from chronic diseases and to find out the importance of task shifting. 
The methodology of this research work includes the study of the importance of task shifting through an online survey in human population community including all adult population in a small city in India, a developing country. With the help of spreadsheet application software MS Excel, the primary data are analysed and the results are compared with various published results obtained through various online sources such as Google Scholar, Pubmed, ScienceDirect, MedlinePlus, ResearchGate, and Academia.edu. Totally 228 primary data samples are used.

\section{RESULTS \& DISCUSSIONS :}

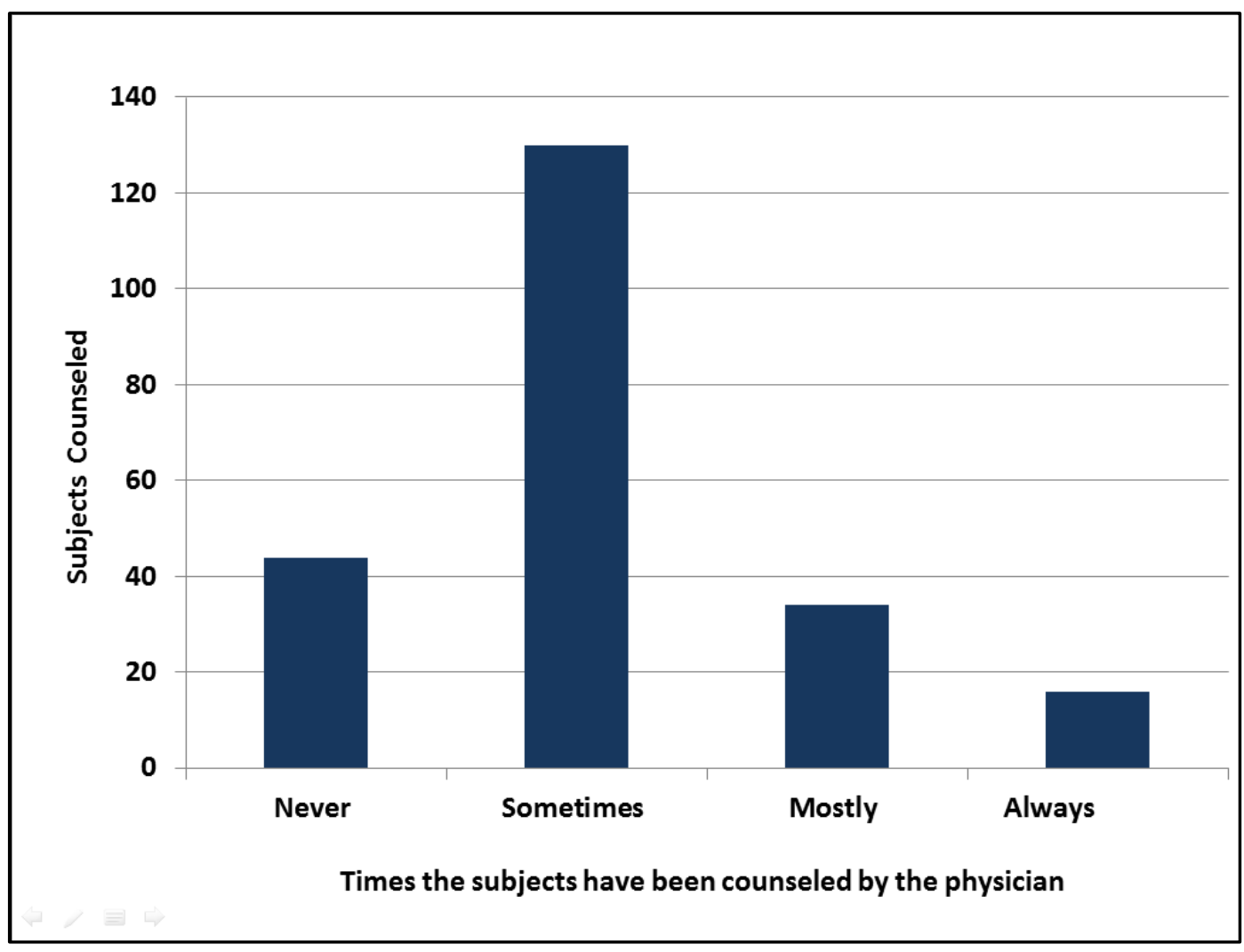

Fig. 1 : Counseling frequency of patients by physicians 


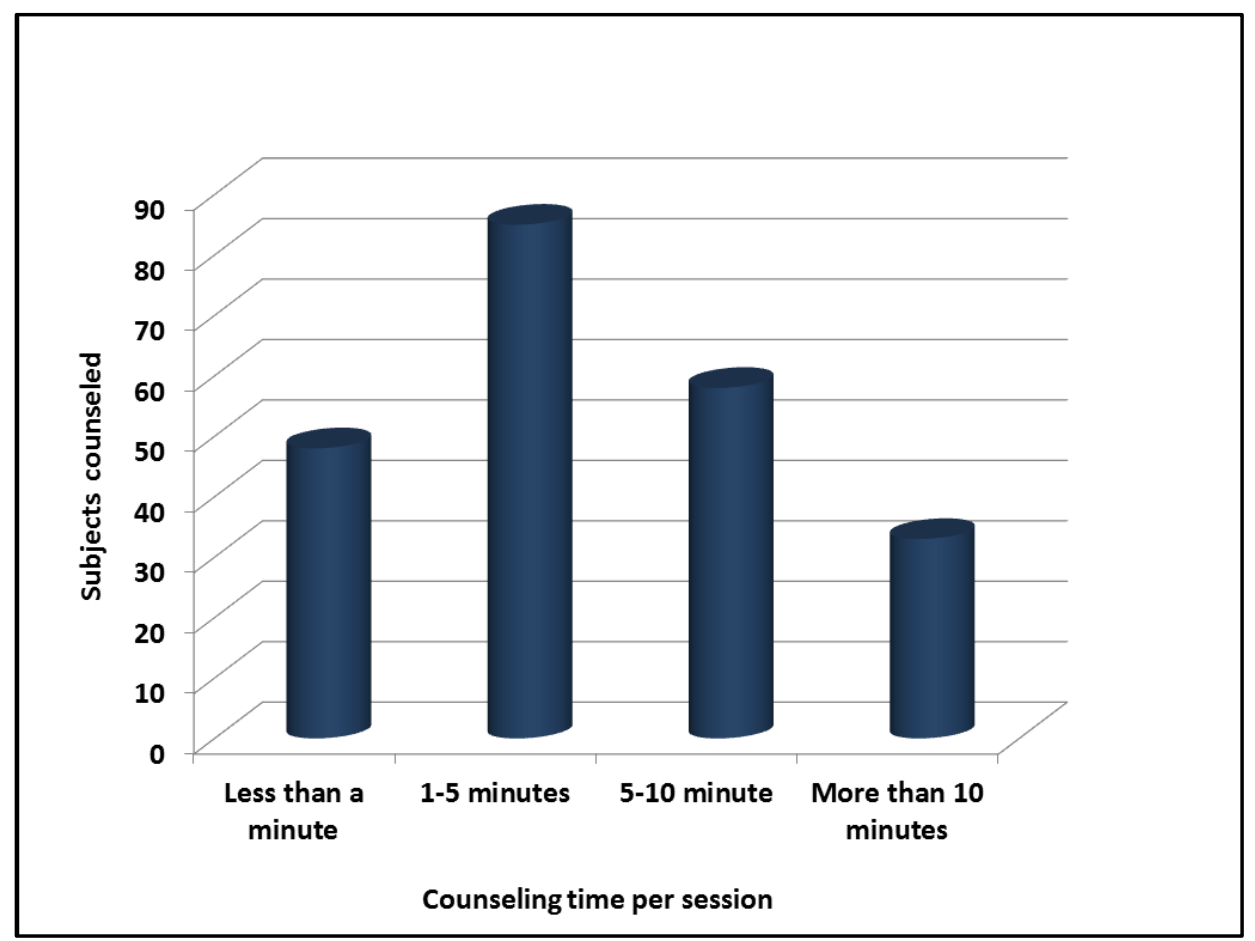

Fig. 2 : Counseling time per session by physicians

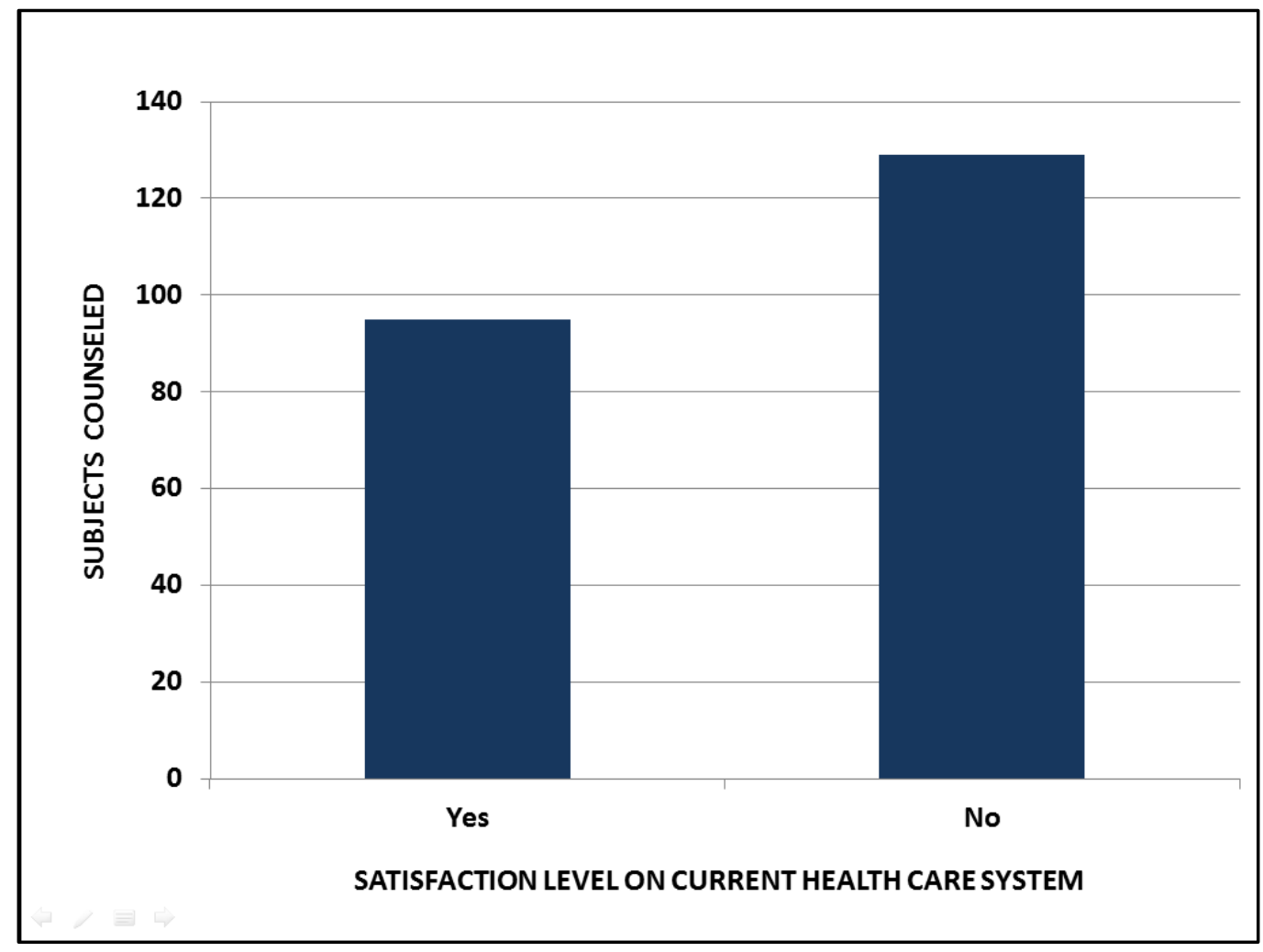

Fig. 3 : Satisfaction level of current healthcare system 


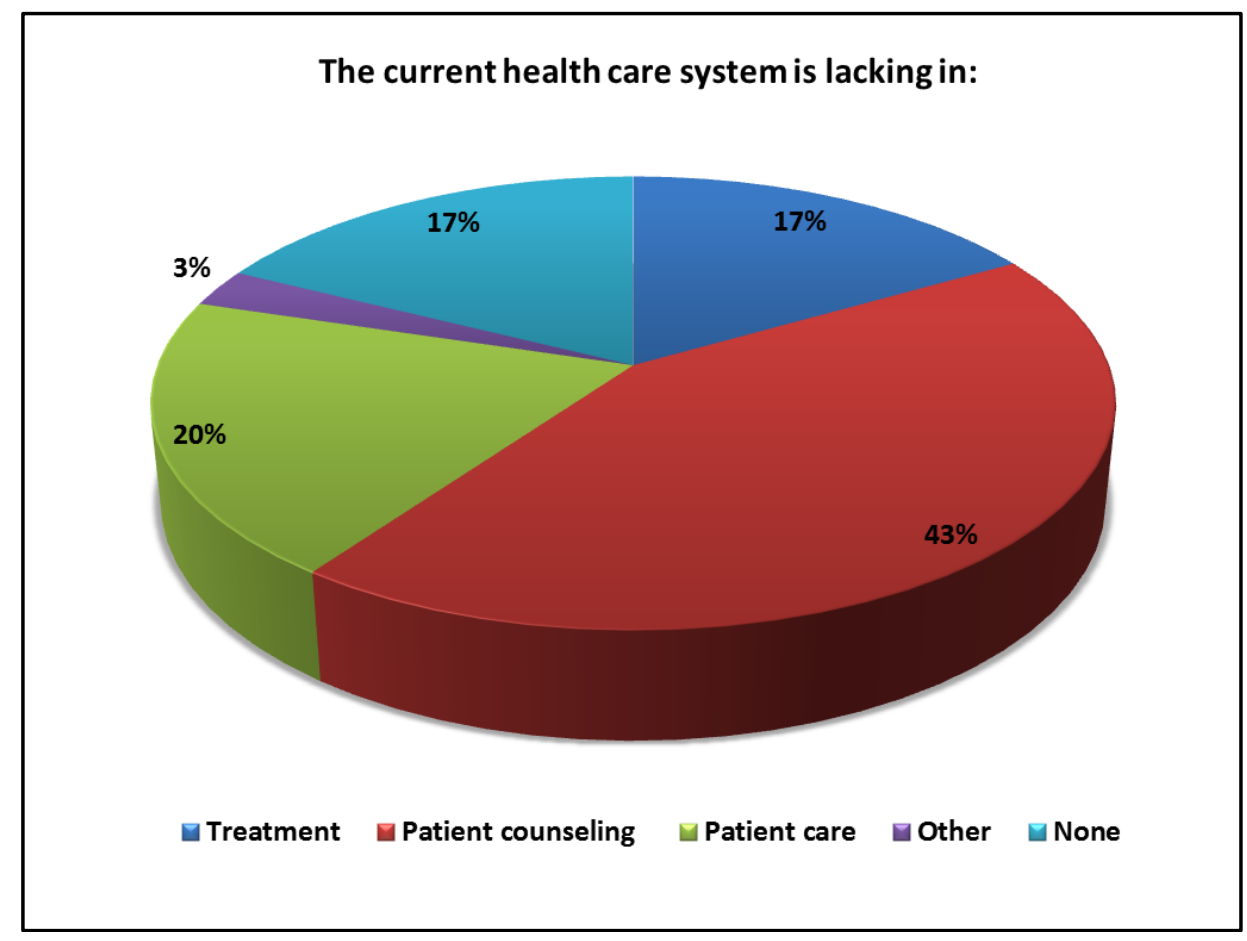

Fig. 4 : Deficiency in the current health system as per out survey.

Out of them, 59.65\% think that counseling should be given and only $41.66 \%$ are satisfied with current health care system while $56.57 \%$ are not satisfied. According to $42.1 \%$ of the general population, the current health care system is lacking in patient counseling and $19.29 \%$ patient care as given in figure 3. The deficiency in the current health system as per out survey is shown in figure 4 can be resolved using the task shifting proposal using paramedical practitioners. Task shifting requires careful attention and evaluation to organization, structure, and resourcing of health services. Crucially, it requires the integration of the concept and roles of new cadres, into the mainstream health system, and integrated strategic reconfiguration of healthcare teams, particularly at primary care and community levels. Without a healthcare team approach, the introduction of new cadres or delegation of tasks to related cadres will invariably remain a fragmented and becomes unsustainable add-on model. In this context, it is observed from review literature that in several countries, task shifting has been enthusiastically and voluntarily taken up by non-governmental organizations (NGOs) with strong community links at the local level, but with limited opportunity and the potential for scaling-up to the national level, as their presence is often geographically. Task shifting holds the potential of enabling countries to build sustainable, cost-effective and equitable health care systems, not only moving forward and closer to the Millennium Development Goals [5], but also the elusive 'Health for All' goal. However, the challenge of achieving and measuring success cannot be underestimated from humanity framework and problem-solving framework. It requires a willingness to learn from those with relevant experience (such as Brazil, Ethiopia, India, Malawi, 
Mozambique and Zambia) and to suspend conventional (and often conservative) wisdom on what can and cannot be done in favor of creativity, humanity, and problemsolving.

\section{RECOMMENDATIONS :}

The above empirical study reveals that a quick and systematic way of providing optimum health services like patient counseling and continued care after core treatment of the patients is needed by utilizing paramedical professionals who have such related knowledge in patient care. Using our preliminary study on improving quality and quick medical/patient care services to the needy people who are suffering from chronic diseases and the information collected by our literature review, we propose following recommendations :

(1) To satisfy all the patients through adequate counseling, and providing continuous care, task shifting is an optimum strategy in healthcare services to any country where there is a scarcity of higher cadre health professionals.

(2) Task shifting is recommended by providing key roles to Paramedical professionals at least for counseling and patient care. It is suggested that the pharmacists should be taken as a key role player between patient and prescriber. In such cases the additional training required is minimal.

(3) By making suitable changes in the Government policy, task shifting can be announced as legal phenomena so that the mindset of the other stakeholders will also change towards acceptance of task shifting.

(4) Imparting suitable training for paramedical staff including Pharmacists, Physiotherapists, Nurses, and other Paramedical graduates, ignored professions in the healthcare sector have to play a crucial role in providing optimum patient care.

(5) Patients should accept such task shifting through proper education on benefits. Changing the patient belief and attitude in accepting task shifting is the primary requirement in providing effectively extended counseling and patient care.

(6) The conservative mindset of the medical professionals like doctors should be changed and they should be made to realize the scarcity and importance of quality service to the needy patients irrespective of the early availability of professional experts by means of creating awareness on right of the patients to get minimum healthcare support in urgency and for their chronic diseases.

(7) The society should accept the task shifting process through the creation of awareness among the people to decrease the cost without compromising the quality for the patients suffering from chronicle diseases.

(8) In some diseases, partly task shifting is possible by training the lay persons like relatives and friends of the patients who are suffering from chronicle diseases by education and training, which creates awareness in patient care.

It is suggested that adequate education, training, and support should be imparted to optimize the effectiveness of task shifting so that the model of task shifting can be a successful alternative for the shortage of healthcare professionals by providing quality health services at minimal cost to satisfy all the stakeholders of the healthcare system in the society. Further study on factors and elemental analysis of task shifting as a strategic concept among health workers using ABCD analysis framework is under progress [26-32].

\section{CONCLUSIONS:}

The empirical study shows that there is a huge burden on health care professionals 
due to a high number of the patient load which leads to the improper patient care and finally leads to the degradation in the quality of health care services. Now time has approached when the term task shifting should be taken seriously especially in the health care sectors. Task shifting is a promising policy option for governments and society to increase the productive efficiency of the delivery of quality healthcare services, increasing the number of services provided at a given quality and cost or to improve the quality and decrease the cost of health services. Future studies should focus on examining the development of new professional cadres or use of parallel cadres such as pharmacists, physiotherapists, Nursing professionals, or any other paramedical graduates that evolve with technology-specific and country-specific alternative human resources. Further to strengthen the evidence, skill mix changes and skill mix improvements need to be evaluated with a quantitative research design to estimate the effect on patient health outcomes, quality of care, and costs.

\section{REFERENCES:}

[1] Beaglehole, R., Epping-Jordan, J., Patel, V., Chopra, M., Ebrahim, S., Kidd, M., \& Haines, A. (2008). Improving the prevention and management of chronic disease in low-income and middleincome countries: a priority for primary health care. The Lancet, 372(9642), 940-949.

[2] World Health Organization. (2007). Task shifting: rational redistribution of tasks among health workforce teams: global recommendations and guidelines, Retrieved on February 6, 2017, from http://www.who.int/iris/handle/10665/4 3821.

[3] Dovlo, D. (2004). Using mid-level cadres as substitutes for internationally mobile health professionals in Africa. A desk review. Human resources for health, 2(1), 7.

[4] Celletti, F., Holloway, J., De Cock, K. M., \& Dybul, M. (2007). Rapid expansion of the health workforce in response to the HIV epidemic. The New England journal of medicine, 357(24), 2510.

[5] Human resources for health: overcoming the crisis. Global Equity Initiative. (2004). Retrieved on February 6, 2017, from http://www.who.int/hrh/documen ts /JLi_hrh_report.pdf.

[6] World Medical Association World Medical Association Resolutions on task shifting from the medical profession. Retrieved on February 6, 2017, from http://www.wma.net/en/30 publications/ 10policies/t4/index.html.

[7] Buttorff, C., Hock, R. S., Weiss, H. A., Naik, S., Araya, R., Kirkwood, B. R., \& Patel, V. (2012). Economic evaluation of a task-shifting intervention for common mental disorders in India. Bulletin of the World Health Organization, 90(11), 813-821.

[8] World Health Organization. (2012). Task shifting to tackle health worker shortages. 2007. Geneva: World Health Organization HIV/AIDS Programme. Retrieved on February 6, 2017, from http://www.who.int/healthsystems/task_ shifting_booklet.pdf.

[9] Mdege, N. D., Chindove, S., \& Ali, S. (2012). The effectiveness and cost implications of task-shifting in the delivery of antiretroviral therapy to HIV-infected patients: a systematic review. Health policy and planning, czs058. 
[10] Labhardt, N. D., Balo, J. R., Ndam, M., Manga, E., \& Stoll, B. (2011). Improved retention rates with low-cost interventions in hypertension and diabetes management in a rural African environment of nurse-led care: a cluster-randomised trial. Tropical Medicine \& International Health, 16(10), 1276-1284.

[11] Rahman, A., Malik, A., Sikander, S., Roberts, C., \& Creed, F. (2008). Cognitive behaviour therapy-based intervention by community health workers for mothers with depression and their infants in rural Pakistan: a cluster-randomised controlled trial. The Lancet, 372(9642), 902-909.

[12] Petersen, I., Ssebunnya, J., Bhana, A., \& Baillie, K. (2011). Lessons from case studies of integrating mental health into primary health care in South Africa and Uganda. International Journal of Mental Health Systems, 5(1), 8.

[13] World Health Organization, World Organization of National Colleges, \& Academic Associations of General Practitioners/Family Physicians. (2008). Integrating mental health into primary care: a global perspective. World Health Organization. Retrieved on February 6, 2017, from http://www.who.int/mental_health/polic $\mathrm{y} /$ services/mentalhealthintoprimarycare/ en/.

[14] Bolton P, Bass J, Neugebauer R, Verdeli H, Clougherty KF, Wickramaratne P et al. (2003). Group interpersonal psychotherapy for depression in rural Uganda: a randomized controlled trial. JAMA, 289, 3117-3124. doi:10.1001/jama.289.23 .3117 .
[15] Bass J, Neugebauer R, Clougherty KF, Verdeli H, Wickramaratne P, Ndogoni L et al. (2006). Group interpersonal psychotherapy for depression in rural Uganda: 6-month outcomes: randomised controlled trial. $\mathrm{Br} J$ Psychiatry, 188, 567-573. doi:10.1192/bjp.188.6.567.

[16] Araya, R., Flynn, T., Rojas, G., Fritsch, R., \& Simon, G. (2006). Costeffectiveness of a primary care treatment program for depression in low-income women in Santiago, Chile. American journal of psychiatry, 163(8), 1379-1387.

[17] Patel, V., Weiss, H. A., Chowdhary, N., Naik, S., Pednekar, S., Chatterjee, S., \& Simon, G. (2010). Effectiveness of an intervention led by lay health counsellors for depressive and anxiety disorders in primary care in Goa, India (MANAS): a cluster randomised controlled trial. The Lancet, 376(9758), 2086-2095.

[18] Patel, V., Weiss, H. A., Chowdhary, N., Naik, S., Pednekar, S., Chatterjee, S., \& Verdeli, H. (2011). Lay health worker led intervention for depressive and anxiety disorders in India: impact on clinical and disability outcomes over 12 months. The British Journal of Psychiatry, 199(6), 459-466.

[19] Lehmann, U., Van Damme, W., Barten, F., \& Sanders, D. (2009). Task shifting: the answer to the human resources crisis in Africa?. Human resources for health, 7(1), 49.

[20] Callaghan, M., Ford, N., \& Schneider, H. (2010). A systematic review of taskshifting for HIV treatment and care in Africa. Human resources for health, 8(1), 8. 
[21] Fulton, B. D., Scheffler, R. M., Sparkes, S. P., Auh, E. Y., Vujicic, M., \& Soucat, A. (2011). Health workforce skill mix and task shifting in low income countries: a review of recent evidence. Human resources for health, 9(1), 1.

[22] Lekoubou, A., Awah, P., Fezeu, L., Sobngwi, E., \& Kengne, A. P. (2010). Hypertension, diabetes mellitus and task shifting in their management in subSaharan Africa. International journal of environmental research and public health, 7(2), 353-363.

[23] Chu, K., Rosseel, P., Gielis, P., \& Ford, N. (2009). Surgical task shifting in subSaharan Africa. PLoS Med, 6(5), e1000078.

[24] Mullan, F., \& Frehywot, S. (2008). Non-physician clinicians in 47 subSaharan African countries. The Lancet, 370(9605), 2158-2163.

[25] Kruk, M. E., Pereira, C., Vaz, F., Bergström, S., \& Galea, S. (2007). Economic evaluation of surgically trained assistant medical officers in performing major obstetric surgery in Mozambique. BJOG: An International Journal of Obstetrics \& Gynaecology, 114(10), 1253-1260.

[26] Aithal, P. S., (2016). Study on ABCD Analysis Technique for Business Models, business strategies, Operating Concepts \& Business Systems, International Journal in Management and Social Science, 4(1), 98-115, DOI : http://doi.org/10.5281/zenodo.161137.

[27] Aithal, P.S., Shailashree, V.T., \& Suresh Kumar, P.M. (2016). Application of ABCD Analysis Framework on Private University System in India. International Journal of Management Sciences and Business
Research (IJMSBR), 5(4), 159-170, DOI

http://doi.org/10.5281/zenodo.161111.

[28] Aithal, P. S., Shailashree, V. T. \& Suresh Kumar, P.M. (2016). The Study of New National Institutional Ranking System using

ABCD

Framework. International Journal of Current Research and Modern Education (IJCRME), 1(1), 389 - 402. DOI : http://doi.org/10.5281/zenodo.1 61077.

[29] Shubhrajyotsna Aithal, Aithal P. S., (2016), ABCD analysis of Dye doped Polymers for Photonic Applications, IRA-International Journal of Applied Sciences, 4(3), 358-378. DOI : http://dx.doi.org/10.21013/jas.v4.n3.p1.

[30] Aithal, P. S. \& Suresh Kumar, P. M. (2016). CCE Approach through ABCD Analysis of 'Theory A' on Organizational Performance. International Journal of Current Research and Modern Education (IJCRME), 1(2), 169-185. DOI: http://dx.doi.org/10.5281/ZENOD O.164704.

[31] Varun Shenoy, \& Aithal P. S., (2016). ABCD Analysis of On-line Campus Placement Model, IRA-International Journal of Management \& Social Sciences, 5(2), 227-244. DOI: http://dx.doi.org/10.21013/jmss.v5.n2.p 3.

[32] Aithal, P. S., Shailashree V. T. \& Suresh Kumar P.M. (2016). Factors \& Elemental Analysis of Six Thinking Hats Technique using ABCD Framework. International Journal of Advanced Trends in Engineering and Technology (IJATET), 1(1), 85-95. DOI : http://doi.org/10.5281/zenodo.240259. 